\title{
Pre-Posttest: Diagnosis of the Achievement Level on Sustainable Business Workshop
}

\author{
Jun Surjanti ${ }^{1, *}$ Rahayu Dewi Soeyono ${ }^{2}$, Tony Seno Aji ${ }^{3}$ \\ ${ }^{1}$ Faculty of Economics and Business, Universitas Negeri Surabaya Surabaya, Indonesia \\ ${ }^{2}$ Faculty of Engineering, Universitas Negeri Surabaya, Surabaya, Indonesi \\ ${ }^{3}$ Faculty of Economics and Business, Universitas Negeri Surabaya, Surabaya, Indonesia \\ *Corresponding author.Email: junsurjanti@unesa.ac.id
}

\begin{abstract}
There are various ways to measure an achievement level on the activity to develop a sustainable business. This study is used to serve as a reference in designing appropriate developmental programs for small business actors. This study aims to analyze the effectiveness of the pre-posttest technique in diagnosing the achievement level of the workshop on sustainable culinary business. The population was 15 culinary SMEs in Surabaya who participated in a sustainable business workshop. The pre-posttest was evaluated using 10 indicators (by selecting correct/B and incorrect/S) to measure the participants' understanding. Data were analyzed using the t-test technique. Results show that the preposttest technique was unable to measure the achievement level of the workshop on the sustainable culinary business. Thus, the pre-posttest technique will not appropriately be used to measure the achievement level of other similar activities/programs to develop a sustainable business.
\end{abstract}

Keywords: pre-posttest, sustainable business, achievement level, SMEs culinary

\section{INTRODUCTION}

The world of entrepreneurship requires research that has a focus and data source, looking for theoretical evidence to relevance it to practical and real-world interests [1]. An entrepreneurial study generally aims to generate economic benefits or create employment; this is what makes entrepreneurship a factor that contributes to the development of a region [2]. A sustainable business will determine the fate of entrepreneurship in the future. At first, sustainable business only focused on entrepreneurial activities and their relationship to environmental problems and solutions [3]. Therefore, [2] suggest that sustainable business research should focus on understanding the qualitative and quantitative dimensions of networks and how they reduce financial challenges and market. Similarly, [4] states that sustainable business needs to collaborate between businesses, business people, and stakeholders (e.g. non-governmental organizations). Responding to these conditions, to improve sustainable business, much research on sustainable business has been carried out [2,5], one of which is how to determine or analyze the achievement level on the programs to develop a sustainable business.
[6] found a technique (applied in the course) that is possibly used to determine the effectiveness of evaluation programs (in addition to a new teaching model to be developed). In addition, Tesch also stated that evaluation (with pre-posttest techniques with experimental group control and comparison) can be used to control managed programs (eg instilling philosophy, seeing individual improvements). In addition, the pretest and posttest activities can provide freedom in increasing success through the prescribed key [7]. They concluded that in the pretest-posttest technique, the error rate can be controlled, so it can be used for the development of business models.

This study is similar to [8], by employing training to change behavior and increase participants' awareness. The success level in changing behavior and increasing awareness is seen (measured) through the achievement level of learning outcomes (seen from right and wrong answers) done by answering multiple-choice questions (MCQ) to the participants. This method is in line with [9] to evaluate problems that arise in the course participants. Meanwhile, [10] also used the pre-post test evaluation technique to foster motivation in performance. However, evaluation using the pre-posttest technique to measure students 'academic progress shows the difference from the 
results of students' academic progress [11]. On the other hand, there is a possibility for the pre-post test evaluation to show discrepancies in certain situations $[12,13]$.

\section{1. $\quad$ Sustainable Business}

Mutuality in the economy should provide a frame of reference for understanding functions and values related to business [14]. In the theory of sustainability, the real practice of business refers to their effort in fulfilling the basic instinct of life [5]. In addition, they illustrate business relationships with sustainability theory in the form of a triple-bottom-line (human, environment, and profit) [14]. From this understanding, sustainable business can be defined as a business that has a response/concern for the impact of social/community (human), the natural environment (environment), and the economic impact (profit) as well as the relation of these factors with current and future business activities.

Starting from the Industrial Revolution [15], sustainability problems have begun to emerge because companies and industries have utilized natural and human resources to meet the needs for energy, food, and others that previously (before the Industrial Revolution) were limited by ecological factors.[16,17] Quoted by [15], a business historian, Geoffrey Jones said that sustainability must be understood as a concept that is built socially and politically (by business) and reflects the interests and values of entrepreneurs, social groups, and organizations involved [18]. Therefore, in a sustainable business, the relationship between related factors (human, environment, and economy) must be harmonious and integrated. One way to improve the logic of sustainable development in business is to seek alignment with business strategies and market dynamics to contribute to the competitive advantage of the business[19].

\subsection{Workshop on Sustainable Culinary Business}

In Taiwan, a culinary business can be trained in Chinese culture, especially to improve and advance the quality and quantity of culinary creativity [20]. Culinary SMEs are the most commonly found culinary business actor in many countries in the world [20,21,22] As a type of business with high future potential, culinary SMEs need training and additional knowledge related to technology and sustainability efforts to achieve effective and sustainable development [23]. There are various types of training employed for sustainable business in culinary SMEs, one of which is through a workshop. From the dictionary (Merriam Webster), a workshop is a meeting where a group of people is involved in discussions and intensive activities on a particular subject or project. The workshop on sustainable culinary business for culinary SMEs Surabaya is a workshop held by a community economic development team consisting of academics/experts from Universitas Negeri Surabaya and Surabaya city government (Department of Cooperatives, Industry and Small Medium Enterprises) and aims to raise awareness of Surabaya culinary SMEs regarding sustainable business. Providing and developing the understanding, information, and knowledge on sustainable business (referring to the SGDs indicator) to culinary SMEs is carried out as part of efforts to develop and improve the quality and quality of culinary creativity as similarly occurred in Taiwan [20], in Dubai [21], as well as in Medan [22].

\subsection{Pre-Posttest Evaluation}

[13] states that pre-posttest can be used to measure knowledge, before and after training to determine participants' abilities (especially on the training contents). Questions or designs from the pre-posttest are designed by the trainer/instructor/related parties. Preposttest is done by answering a series of questions with comparable difficulties. The score is then compared and evaluated to provide information about the changes in knowledge produced. The pre-posttest is not the best possible method used in any training. Short courses, which last a day or more, may not be appropriate to employ this technique as it has time requirements for managing and analyzing data before and after the exam. In addition, pre-and post-training exams are focused on building skills relations, for example, effective counseling skills training, may be difficult to make and assess. [12] also stated that assessing projects (before and after training) and writing the feedback given by students to peer projects, with a specific duration of times on assessment training caused a significant decrease in the difference between student ratings and instructor ranking.

\subsection{Evaluation Technique}

When assessing the success/achievement of a certain program/model/ method, there are a 'must' preliminary steps, such as diagnosing, followed by designing, implementing, and evaluating. Referring to it, diagnosing (first step) serves s a stepping stone especially to design a model prototype (to be implemented in a program) [24]. Good evaluation needs to be appropriately and suitably assessed based on aspects: attitude (obtained through observation), knowledge (from written/spoken assignments), and skills (practices, products, projects, portfolios, and/or other techniques) [25]. According to [26] in traditional evaluations, emphasizes the scientific method in which the reliability and validity of data become key and they make the accuracy of methodology the main criteria for quality evaluation. In addition, traditional evaluation requires evaluators to be objective and neutral and only consider results $[12,26]$. Before selecting specific methods and/or data collection techniques used in evaluation studies, evaluators must determine what approach should be taken and how it will be done [27]. This is mainly due to aspects that need to be considered before an evaluation is carried out (problems that may arise). Therefore, before making an appropriate evaluation technique/method for a program, 
researchers/ related parties need to make an initial diagnosis of whether the method is appropriate or can explain/determine the results of the program.

This study is to analyze how the evaluation technique (pre-posttest) is effective to be used in measuring the program achievement level (workshop on sustainable culinary business).

\section{METHOD}

This study is a qualitative study using an experimental approach to determine the effectiveness of the pre-posttest technique to measure the achievement level of workshops on sustainable business for culinary SMEs actors. The population was 15 SMEs actor located in the Culinary Center of Bungkul Park Surabaya who participated in the sustainable culinary business workshop. The scoring (pre-posttest) was conducted through ten indicators (by answering correct/B and incorrect/S) before (pre) and after (post) the activity (workshop) carried out. The results were, then, analyzed using a t-test to determine the changes in participants' outcomes of both tests (pre and post).

\begin{tabular}{|l|l|l|}
\hline Pretest & Posttest \\
(Result) & (Result) \\
WORKSHOP ON & \\
SUSTAINABLE & WORKSHOP ON \\
CULINARY BUSINESS & SUSTAINABLE \\
& CULINARY BUSINESS \\
\hline
\end{tabular}

Figure 1 Design of Pre-posttest Evaluation

\section{RESULT AND DISCUSSION}

Population was 15 SMEs culinary actor located in Culinary Center Bungkul Park Surabaya. SMEs characteristics are determined from: 1) sex (33.3\% male and $66.7 \%$ female); 2) products ( $80 \%$ food seller and $20 \%$ beverages seller; 3 ) age (40\% aged $31-40$ years, $20 \%$ aged20 41-50 years, and 20\% no information); 4) monthly income $(6.7 \%$ earned IDR 1.000 .000 $2.000 .000 ; 13.3 \%$ earned IDR 2.100.000-3.000.000, $6.7 \%$ earned IDR 3,100,000-4,000,000, $13.3 \%$ earned IDR 4.100.000-5.000.000, and 60\% no information).

\subsection{Results}

Although many studies/research found that preposttest can determine the achievement level on certain programs/activities $[9,10,11,27]$. However, this study on the contrary did not have a similar finding as it tends to in line with other studies $[12,13]$ on how this technique (pre-posttest) cannot directly measure the achievement level of training/workshop. The result indicates that preposttest techniques did not significantly and effectively determine the achievement level of a workshop on sustainable business for culinary SMEs actors in Surabaya (proved by $\alpha>0.05$ ). Though in the early calculation (see Table 2 and 3), the analysis seemingly disclosed that it can show the achievement level of the program (workshop). Consequently, pre-post tests cannot portray the achievement level of the activity.

\subsection{Discussion}

Data obtained (from pre-posttest) later were analyzed to determine the achievement level of the activity (workshop on sustainable culinary business) (see table 1). Data were, then, compared and analyzed using a t-test to measure the tendency on achievement level (knowledge mastery/understanding) from participants before and after the program (workshop).

Table 1. Result of Pre-Posttest on Sustainable Business

\begin{tabular}{|c|c|c|c|}
\hline \multirow{2}{*}{ Respondent } & \multicolumn{2}{|c|}{ Result } & \multirow{2}{*}{ Criteria } \\
\cline { 2 - 3 } & Pre & Post & \\
\hline 1 & 7 & 8 & Incline \\
\hline 2 & 8 & 10 & Incline \\
\hline 3 & 9 & 7 & Decline \\
\hline 4 & 9 & 7 & Decline \\
\hline 5 & 9 & 7 & Decline \\
\hline 6 & 10 & 9 & Decline \\
\hline 7 & 9 & 9 & Constant \\
\hline 8 & 9 & 8 & Decline \\
\hline 9 & 7 & 8 & Incline \\
\hline 10 & 5 & 9 & Incline \\
\hline 11 & 9 & 10 & Incline \\
\hline 12 & 7 & 10 & Incline \\
\hline 13 & 6 & 10 & Incline \\
\hline 14 & 7 & 4 & Decline \\
\hline 15 & 7 & 4 & Decline \\
\hline
\end{tabular}

Table 1 shows seven participants showing an increase in their outcomes (from pre-post test results), the other seven participants show a decrease in their outcomes (from pre-posttest). However, there is one participant who remained constant (did not show any changes on preposttest). The obtained data (scores from both pre-test and

Table 2. Paired Samples Statistics

\begin{tabular}{|l|l|l|l|l|l|}
\hline \multicolumn{2}{|c|}{} & Mean & N & $\begin{array}{l}\text { Std. } \\
\text { Deviation }\end{array}$ & $\begin{array}{l}\text { Std. Error } \\
\text { Mean }\end{array}$ \\
\hline $\begin{array}{l}\text { Pair } \\
1\end{array}$ & Pretest & 7.8667 & 15 & 1.40746 & .36341 \\
\cline { 2 - 6 } & Posttest & 8.0000 & 15 & 1.96396 & .50709 \\
\hline
\end{tabular}


Table 3. Paired Samples Correlations

\begin{tabular}{|l|l|l|l|l|}
\hline \multicolumn{2}{|l|}{} & N & Correlation & Sig. \\
\hline Pair 1 & Pretest \& Posttest & 15 & .026 & .927 \\
\hline
\end{tabular}

Table 4. Paired Samples Test

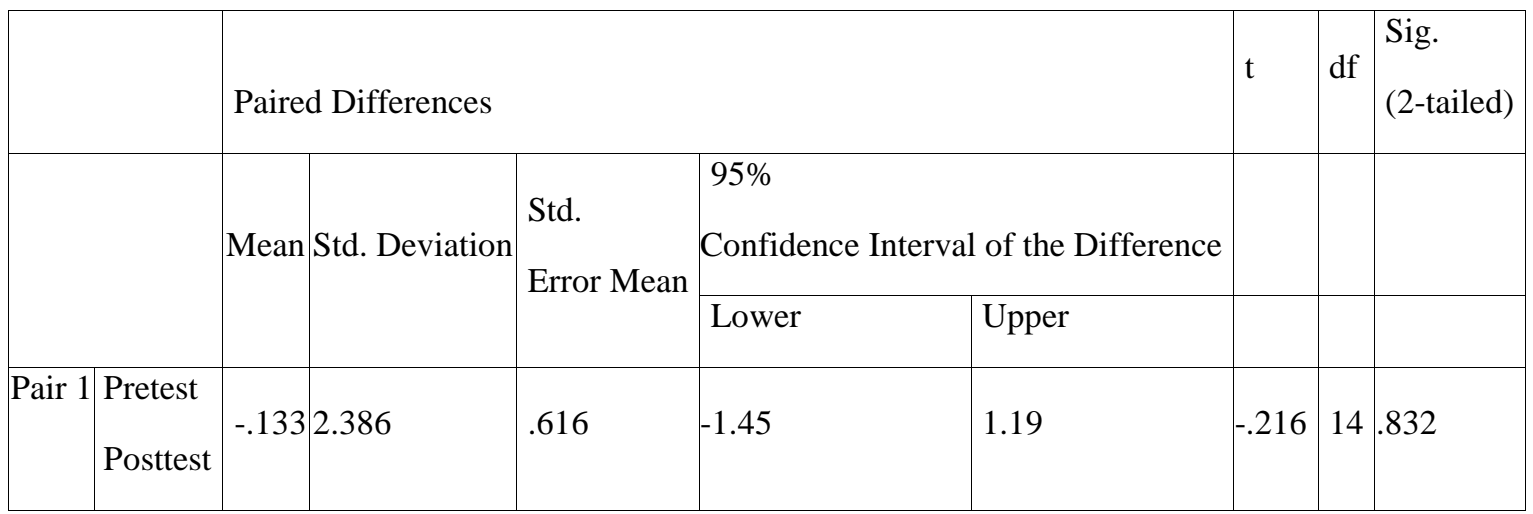

post-test) were calculated using a t-test to determine the different statistic values from pre and post-tests (see Table 2).

Table 2 presents the average value for pre-test as 7.8667 and post-test as 8.000 meaning that the post-test average value is higher than pre-test after the activity is carried out (workshop). Subsequently, a correlation test for the values of the pre-post test was conducted to look for the correlation of both results (pre-posttests) (see Table 3).

Data analysis shows there is a correlation of pre-posttests on a workshop of sustainable culinary business (0.026) with a significance of 0.927 . For the following procedure, data from correlation samples were tested using t-test (scored as -0.216 with average value as -0.13333 and deviation standard of 2.38647 as well as Sig. $(\alpha)$ as 0.832). The Sig. value of pre-posttests did not significantly explain the achievement level on a workshop $(\alpha>0.05)$.

\section{CONCLUSION}

Result proves that the pre-posttest technique cannot significantly distinguish the result of the workshops. This indicates that its results cannot be used as a measurement tool to determine the success of a workshop on sustainable culinary business. Overall, it is concluded that to measure the success rate of a training/workshop, the pre-post test evaluation technique is not appropriate to be applied because training/workshops focus on the participant's performance during the program as well as the program duration (which in this case are not discussed in this study) [13,24].

\section{SUGGESTION}

To evaluate the success of the workshop on sustainable culinary business, the researcher or team needs to design evaluation techniques focusing on the participants' performance during the training/program. For future study, researchers suggest employing performance evaluation techniques in determining the achievement level of any training/program to develop a sustainable business.

\section{IMPLICATION}

As this study purposes to diagnose the use of preposttest in measuring the achievement level, it implies determining an appropriate technique used to measure the achievement level of any future workshops/training activities to develop SMEs. Furthermore, to carry out this technique, thoroughly, it is necessary to analyze each point/item test (referring to the 10 SDGs indicators) as the achievement indicator for the evaluation. Applying appropriate evaluation techniques (considering the objectives/goals of the activity) is needed because without finding the achievement level, an activity cannot be determined as successful or fail.

\section{ACKNOWLEDGMENT}

Best gratitude delivered to the Ministry of Research, Technology, and Higher Education and Universitas Negeri Surabaya for supports by the funding program 2019 given through the Directorate of Research and Community Service Program of Universitas Negeri Surabaya. 


\section{REFERENCES}

[1] Ahmetoglu, G., Chamorro-Premuzic, T., Klinger, B., \& Karcisky, T. (2017). The Wiley Handbook of Entrepreneurship, 1-501. https://doi.org/10.1002/9781118970812

[2] Sarango-Lalangui, Paul, Jane L.S. Santos, and Esther Hormiga. 2018. "The Development of Sustainable Entrepreneurship Research Field" Sustainability 10(6), 2005. https://doi.org/10.3390/su10062005.

[3] Del Baldo, M., Baldarelli, MG. (2017). Renewing and improving the business model toward sustainability in theory and practice. Int J Corporate Soc Responsibility 2(3). https://doi.org/10.1186/s40991-017-0014-z

[4] Bocken, N. (2014). Sustainable Business: The New Business as Usual? Journal of Industrial Ecology, 18(5), 684-686. https://doi.org/10.1111/jiec.12134

[5] Petrini, M., \& Pozzebon, M. (2010). Integrating Sustainability into Business Practices: Learning from Brazilian Integrating Sustainability into Business Practices : Learning from Brazilian Firms. BAR, 7(4).

[6] Tesch, A. (2016). Implementing Pre-Post Test Designs in Higher Education Evaluations. https://doi.org/10.1002/ev

[7] Yasin, M., Mohamed Saeed, S., (JV) Rajendran, J., \& Sinanoglu, O. (2016). Activation of Logic Encrypted Chips: Pre-Test or Post-Test? Design, Automation \& Test in Europe Conference\& Exhibition, 139-144. https://doi.org/10.3850/9783981537079_0687

[8] Samuel, T., Azen, R., \& Campbell-Kyureghyan, N. (2019). Evaluation of Learning Outcomes Through Multiple Choice Pre- and Post-Training Assessments. Journal of Education and Learning, 8(3), 122. https://doi.org/10.5539/jel.v8n3p122

[9] Chudzicki, C., Chen, Z., Zhou, Q., Alexandron, G., \& Pritchard, D. E. (2015). Validating the pre/posttest in a MOOC environment. PERC Proceedings, Edited by Churukian, Jones, and Ding, 83-86. https://doi.org/10.1119/perc.2015.pr.016

[10] Apter, M. J., \& Boorer, D. R. (2015). The Effect of Multiple-Choice Pre-Testing on Post-Test Performance in Programmed Instruction. Programmed Learning and Educational Technology, $8(2)$, 125-130. https://doi.org/10.1080/1355800710080208

[11] Schalich, M. E. (2015). Analysis of Pre Test and Post Test Performance of Students in a Learning Center Model at the Elementary School Level

[12] Fine, Allison H., Colette E. Thayer, and Anne Coghlan. (2000). Program Evaluation Practice in the Nonprofit Sector, Nonprofit Management \& Leadership. $\quad 10(3)$ : 331-339. https://doi.org/10.1002/nml.10309
[13] O'Leary, Jessica L. and Glenn D. Israel. (2019). Capturing Change: Comparing Pretest-Posttest and Retrospective Evaluation Methods. https://edis.ifas.ufl.edu/pdf/WC/WC13500.pdf

[14] Jackson, K. T. (2018). Economy of Mutuality: Equipping the Executive Mindset for Sustainable Business. Managing Sustainable Business, 293-315. https://doi.org/10.1007/978-94-024-1144-7_15

[15] Bergquist, Ann-Kristin. 2017. Business and Sustainability: New Business History Perspectives. Working Paper. Harvard Business School. https://www.researchgate.net/publication/32050584 5_Business_and_Sustainability_New_Business_His tory_Perspectives

[16] Clark, Gregory. (2004). A Farewell to Alms: A Brief Economic History of the World. Princeton: Princeton University Press.

[17] Pomeranz, Kenneth. 2000. The Great Divergence. China, Europe, and the Making of the Modern World Economy. Princeton: Princeton University Press.

[18] Jones, Geoffrey. 2017. Profits and Sustainability. A Global History of Green Entrepreneurship. Oxford: Oxford University Press.

[19] Morioka, S.N. \& de Carvalho, M.M. 2017. Discussing sustainability in business context and in performance disclosures: analysis of Brazilian case studies. Gest.Prod., São Carlos, v. 24, n. 3, p. 514525, 2017. http://dx.doi.org/10.1590/0104$530 \times 2665-16$

[20] Peng, K. L., Lin, M. C., \& Baum, T. (2013). The constructing model of culinary creativity: An approach of mixed methods. Quality and Quantity, 47(5), 2687-2707. https://doi.org/10.1007/s11135012-9680-9

[21] DTCM \& Dubai Chambers. (2009). A Small and Medium Enterprises Development Perspective of the Hospitality Industry in Dubai. Agency of Department of Economic Development of the Government of Dubai. ded.ae/StudiesAndResearchDocument/DUBAI_SM E_Hospitality_Study.pdf

[22] Sembiring, Rasmulia. 2016. Impact of Human Resources' Knowledge and Skills on SMEs' in Medan City, Indonesia. International Journal of Management, Economics and Social Sciences 2016, Vol.5(3): 95 - 104. ISSN 2304 - 1366. http://www.ijmess.com

[23] Szczepańska-Woszczyna, Katarzyna \& Pysz, Joanna. 2016. Sustainable Business Development Through Leadership in SMEs. Economics and Management. 8. 57-69. 10.1515/emj-2016-0024.

[24] Jones, Paul \& Packham, Gary \& Pickernell, David $\&$ Beynon, Malcolm. (2013). Evaluating the Impact of Different Training Methods on SME Business Performance. Environment and Planning $\mathrm{C}$ 
Government and Policy. 31. 56-81. 10.1068/c12113b.

[25] Dinas Pendidikan dan Kebudayaan Republik Indonesia. Peraturan Menteri Pendidikan dan Kebudayaan No. 23 tahun 2016 tentang Standar Penilaian Pendidikan. (2016).

[26] Calidoni-Lundberg, F. (2006). Evaluation: definitions, methods, and models, An ITPS framework. Working Paper. ITPS, Swedish Institute for Growth Policy Studies. https://www.tillvaxtanalys.se/download/18.1af15a1 f152a3475a818975/1454505626167/Evaluation+de finitions+methods+and+models-06.pdf

[27] Powell, R.R. 2006. Evaluation Research: An Overview. Library Trends, 55(1), 2006. https://pdfs.semanticscholar.org/b26f/698b0af7a82 ee40d2d2c77b52fcdef05db43.pdf. Retrieved on July 30, 2019. 